\title{
Modelling hard rock jointed pillars using a distinct element and discrete fracture network approach considering the effect of a clay-filled shear structure
}

\author{
JJM Muaka SRK Consulting (South Africa) (Pty) Ltd, South Africa
}

S Duma Zimplats, Zimbabwe

P Mushangwe Zimplats, Zimbabwe

L Gardner Implats, South Africa

T Chindedza SRK Consulting (South Africa) (Pty) Ltd, South Africa

J Walls SRK Consulting (South Africa) (Pty) Ltd, South Africa

WC Joughin SRK Consulting (South Africa) (Pty) Ltd, South Africa

\begin{abstract}
This paper presents a methodology to design jointed hard rock pillars transacted a clay-filled shear zone at Ngezi mine, Portal 4 (P4), in Zimbabwe. The nature of the problem is highly complex due to the large number of joints and possible shear zone configurations. On the mine, the shear zone can be found either above, below or within the ore zone. It was observed underground that large footwall heaves occur where the shear zone is in the footwall, while hanging wall fallouts were recorded where the shear zone is on the hanging wall. Tensile fracturing and large pillar lateral displacements were also observed and associated with the existence of the shear structure.
\end{abstract}

An investigation into the behaviour of pillars under these conditions were carried out using $2 D$ numerical modelling. A discrete element approach in the software program UDEC was used to account for the large number of joints within the rock mass. Tensile fracturing observed in the failed pillars was simulated by using a voronoi tessellation background and calibrating the shear strength properties at the boundaries of the voronoi blocks in order to replicate macroscopic responses of the intact rock measured in the laboratory, i.e. unconfined compressive strength (UCS) test and indirect tensile test - Brazilian (UTB). This calibration exercise was conducted by replicating the actual UCS, UTB, Young's modulus and Poisson's ratio in UDEC and adjusting the contact properties until a satisfactory correlation between the modelled and laboratory results was obtained.

A discrete fracture network (DFN) approach was utilised to assimilate structural data from a mapping exercise conducted on the mine. The built-in DFN generator in the program 3DEC was used to generate stochastically several 3D DFNs from which, 2D sections were cut and imported into the 2D program, UDEC. Due to time constraint, only two DFNs (DFN 1 and DFN 2) were effectively examined and were selected such that DFN 1 incorporated a low angle random joint set. Four shear zone configurations were examined for each DFN including, shear in the footwall, in the hanging wall, in the orebody and a case without shear structure.

Based on the current mine design, three pillar sizes were examined, 2, 4 and $6 \mathrm{~m}$ or a total of 24 UDEC simulations. In the end, it was found that the models replicated satisfactorily the pillar behaviour and mechanisms observed underground together with the expected pillar peak strength. The findings of these study should constitute a vital input into the evaluation and assessment of future mining options at NGEZI, P4, while the methodology followed may be applied where highly jointed rock mass are intersected by a shear structure.

Keywords: pillar design, discrete element modelling, voronoi tesselation 


\section{Introduction}

The Zimbabwe's principal platinum-group metals producer Ngezi is located in the northern part of Zimbabwe in Mashonaland West Province. With estimated reserves of 107.4 million ounces of platinum, it is regarded as one of the largest platinum deposit in Southern Africa. Ngezi alongside Hartley are two of several platinum group metals (PGM) bearing deposits hosted in Zimbabwe's Great Dyke, which is a $450 \mathrm{~km}$-long mafic and ultramafic intrusive structure that runs through central Zimbabwe, with a maximum width of just $11 \mathrm{~km}$. The orebody at Ngezi covers an area of $8 \mathrm{~km}$ north to south and 1 to $1.5 \mathrm{~km}$, east to west and outcrops at surface. The sulphide ore is oxidised at the outcrop, but remains unweathered at depths in excess of $20 \mathrm{~m}$. Figure shows a map of Zimbabwe together with the location of the great dyke and platinum bearing deposits.

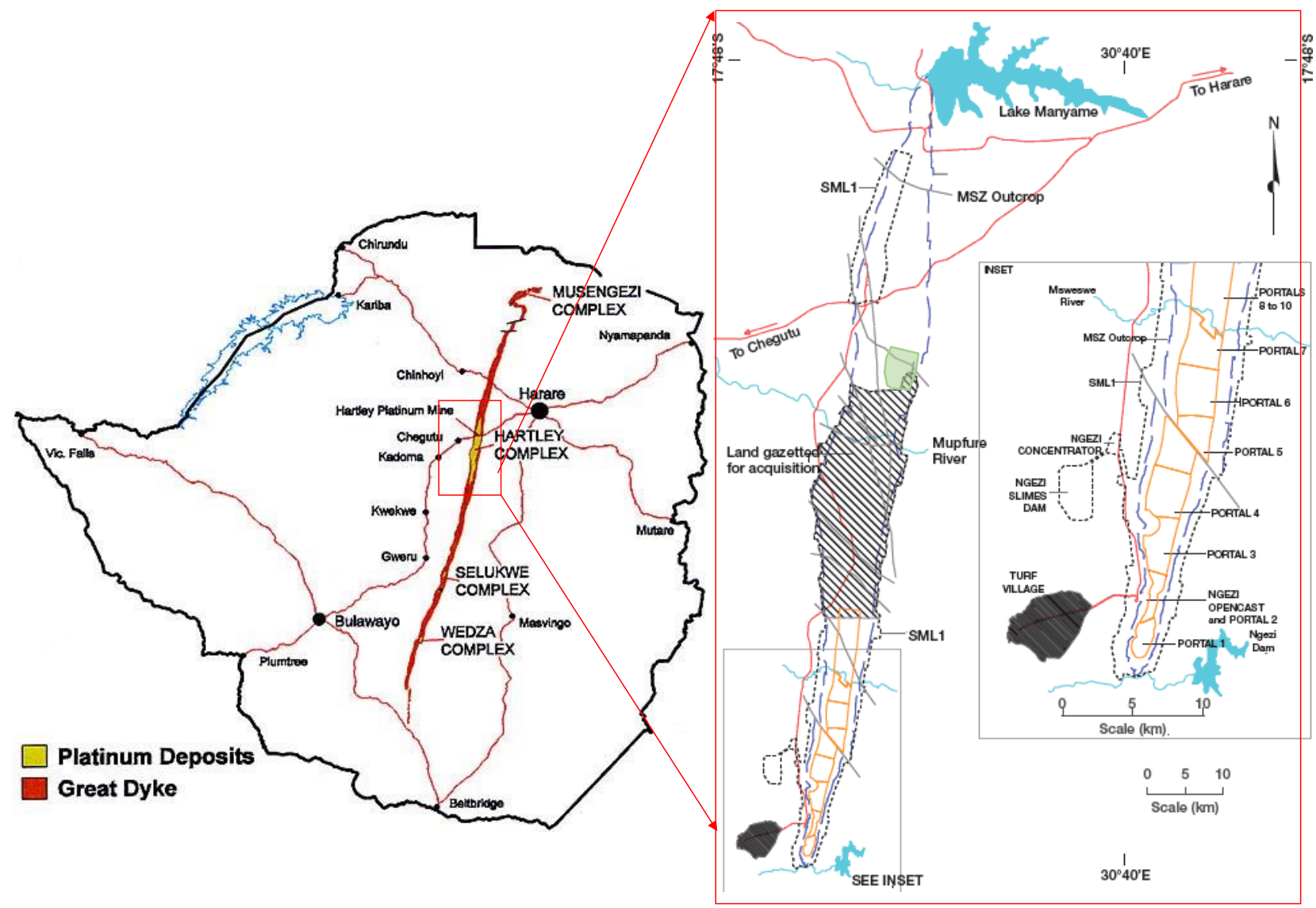

Figure 1 Ngezi P4 Bimha shaft location

The shallower portion of the orebody between 20 and 50 m was once mined in open pit. Ngezi was developed in 2006 as a result of an expansion phase conducted by Zimplats. P4, which is the studied area was fully constructed in 2011. In 2014 the operation had the annual production estimated at 239,700 ounces of platinum in matte.

Events that have compromised stability of underground workings were recently experienced at Portal 4 affecting in the process over $50 \%$ of the mine footprint. The instability is believed to have been initiated by the deterioration of ground conditions associated with a major shear structure, the Mutambara shear, which transgresses through half of the mine area.

Following these events, rock engineers agreed that conventional empirical approaches are inappropriate for designing pillars in these complex geotechnical conditions and numerical modelling was proposed as a necessary alternative going forward to improve the confidence in the empirical methods. 


\section{Data and methodology}

\subsection{Underground observations}

Apart from the presence of a major shear structure, one important characteristic of the rock mass at Ngezi is that it is highly jointed. The joint and the major shear structure may contain variable proportions of minerals such as serpentinite, talc, mylonite and quartz crystal inclusion. For the sake of this study the shear structure was considered to be filled with clay minerals.

Underground visits to the areas affected assisted with the visualisation of failure mechanisms, which as illustrated in Figure involve:

- Unravelling of joint bound blocks and wedges in the hanging wall (HW) with the shear in HW (Figure $2(a)$ ).

- Tensile failure in the shotcrete against the sidewall of a pillar in the immediate proximity of fall of ground with the shear occurring in the HW (Figure 2 (b)).

- Buckling of heave of the footwall (FW) where the shear occurs in the FW (Figure 2 (c)).

- Stress induced tensile fracturing and mobilisation of joints within the pillars (Figure 2 (d)).

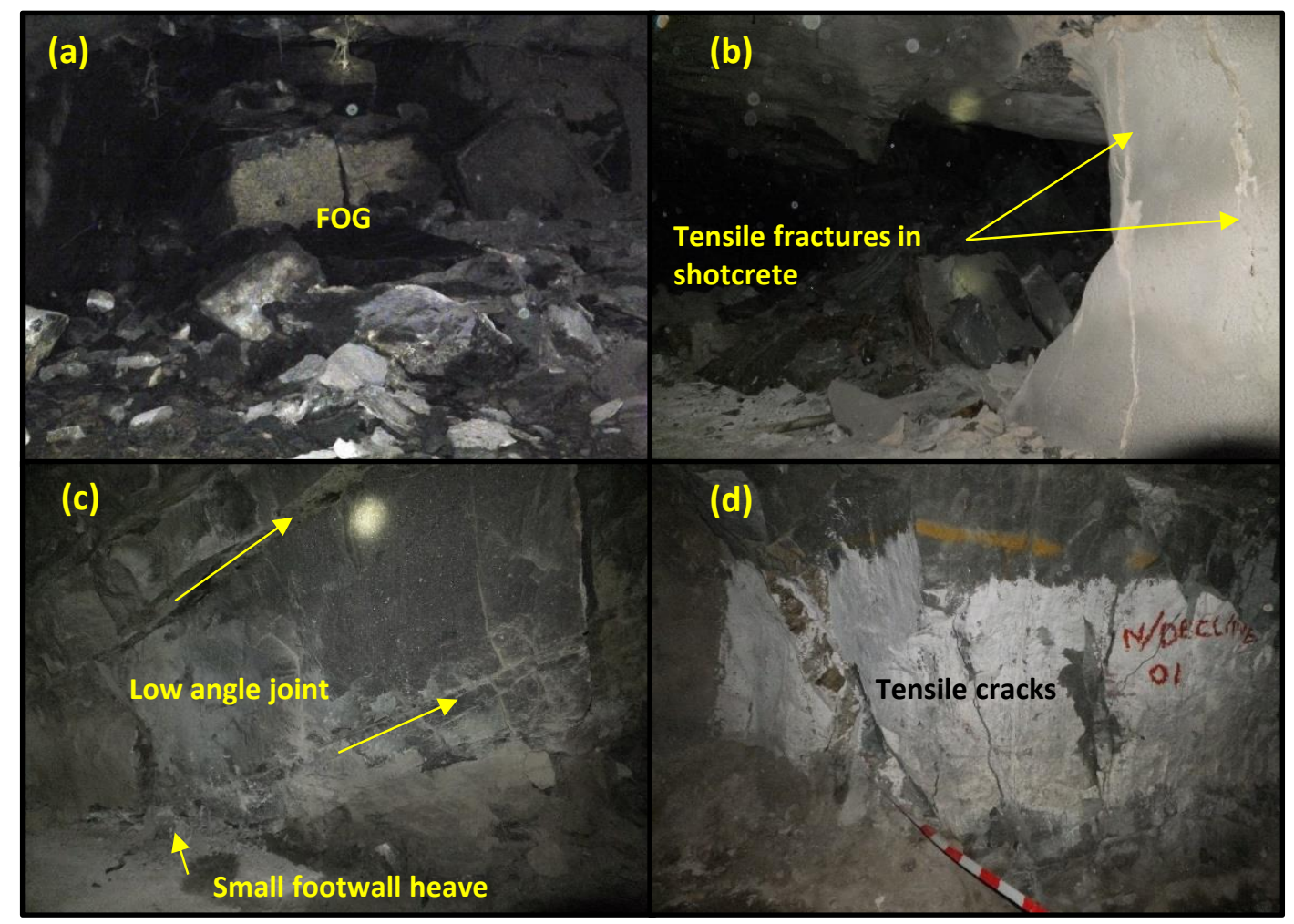

Figure 2 Underground observations: (a) massive fall of ground associated with the presence of the shear zone in the hanging wall; (b) shotcrete failure against a pillar walls due to excessive bulging; (c) in-filled low-angle jointing and small scale footwall heave associated with sheared material in the footwall; and, (d) clearly apparent stress-induced tensile fractures and joint mobilisation within the pillar

\subsection{Structural mapping}

Joint mapping was undertaken at different areas of $\mathrm{P} 4$ as indicated in Figure 3. The joint mapped were further processed in a bid of subdividing the area in different structural domains. As can be seen in Figure 3, while jointing may have differed from place to place, at the scale of the shaft it was found reasonable to assume a 
single structural domain. Table 1 presents a summary of the geometric parameters for the four major joint sets identified in the stereographic projection using the program DIPS version 6.0 (Rocscience Inc. 2012). There are three main sub-vertical sets, of which two are highly spaced (Set 1 and 3). Set 2 is moderately spaced and Set 4 is a flat dipping set.
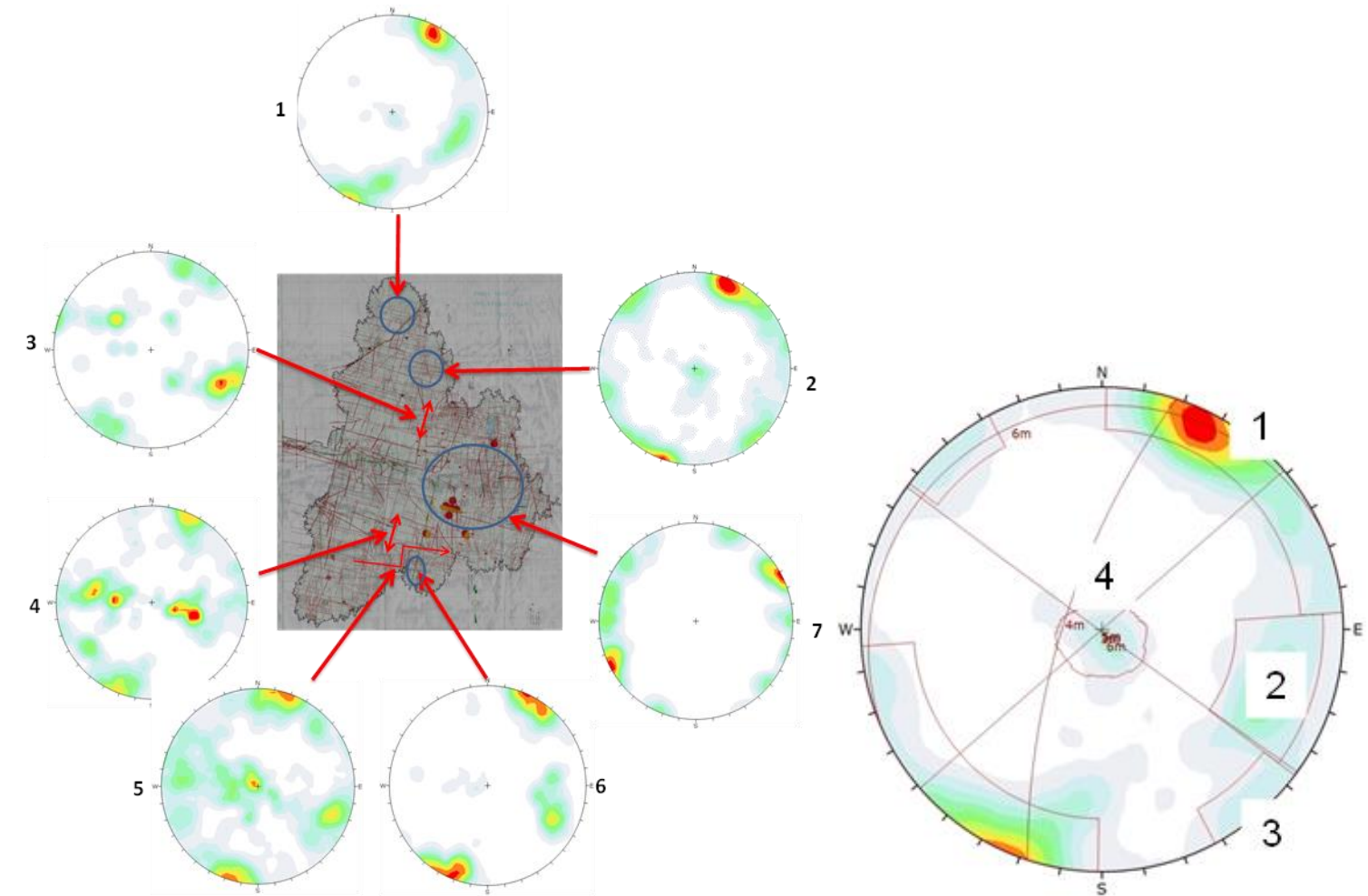

Figure 3 Summary of joint mapping data. Areas mapped (left). Stereographic projection of the main joint sets

The program DIPS also provides a Fisher's coefficient $K$ of dispersion for each joint set. The higher the value of $\mathrm{K}$ the lower the variability about the average values of dip and dip direction within a particular joint set. For instance, the dispersion within joint set 3 is the lowest, and the highest in joint set 1.

Table 1 Summary of major joint set geometric parameters

\begin{tabular}{llll}
\hline Joint set & Dip $\left(^{\circ}\right)$ & Dip direction $\left(^{\circ}\right)$ & Fisher's K \\
\hline 1 & 88 & 215 & 14 \\
2 & 72 & 287 & 40 \\
\hline 3 & 90 & 318 & 88 \\
\hline 4 & 5 & 336 & 43 \\
\hline
\end{tabular}




\subsection{Laboratory testing programmes}

Rock and joint samples were collated onsite as part of the study and were sent to the laboratory for testing. The results of testing were combined with results of previous testing campaigns at $\mathrm{P} 4$ and the surrounding portals (P3, P4, P5 and P6). In total, 27 triaxial compressive strength, 17 base friction angle on saw cut fractures (BFA) and 12 direct shear on open joint (SHJO) tests were carried out as part of the present study. Figure 4 summarises all the uniaxial compressive (UCS), triaxial compressive (TCS) and Brazilian tensile (UTB) strength tests available for the study in terms of major versus minor principal stress and classified according to the sample location. Irrespective of the portals, the orebody, footwall and hanging wall were found to have similar strength properties. This observation is reinforced by the fact that the orebody is not defined by change in lithology but rather grade.

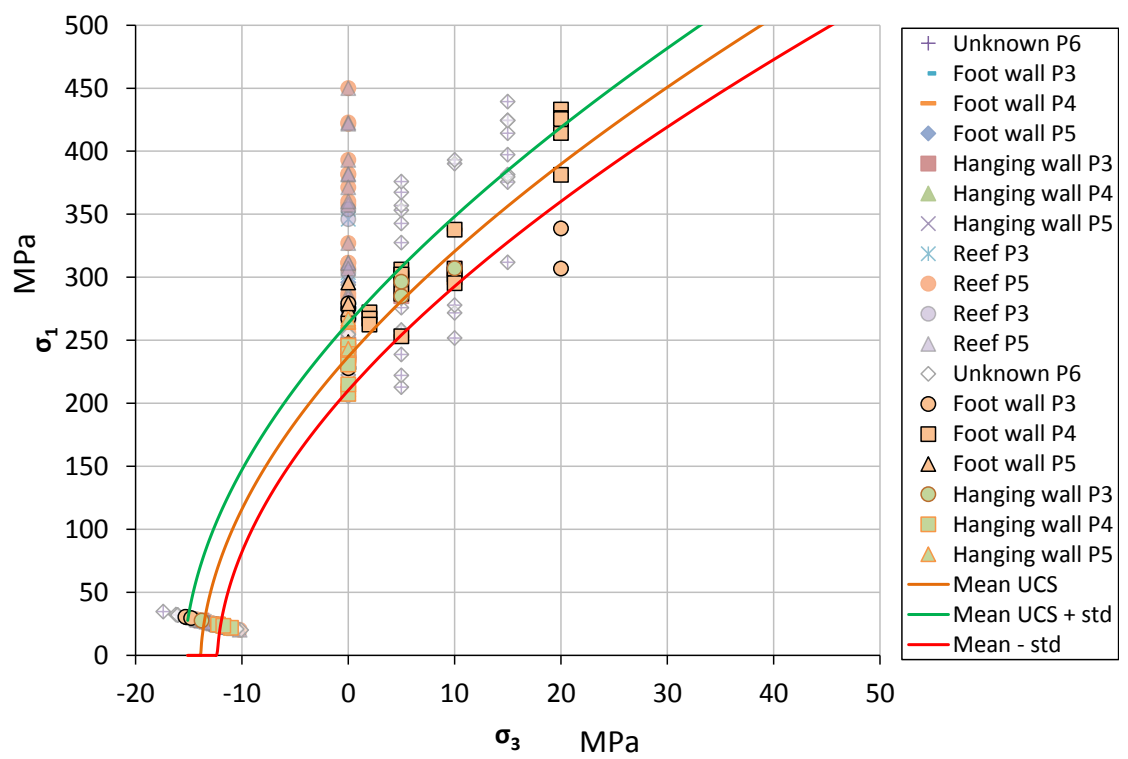

Figure 4 Summary of rock testing programmes

The results for base friction angle, direct shear and UCM tests are consolidated in Table 2. Expectedly, BFA results were consistently higher than peak friction angles obtained in the SHJO tests. The SHJO testing results were considered conservative and therefore preferred for the modelling. The UCM allowed for measuring the values of the Young's modulus and Poisson's ratio of the rock included in Table 2. It is also important to note that UCS tests where failure developed along the pre-existing discontinuities rather than the rock fabric itself were discarded.

Table 2 Summary of results of base friction, shear on open joint and uniaxial compressive tests

\begin{tabular}{|c|c|c|c|c|c|c|c|c|}
\hline \multirow{2}{*}{ Parameter } & \multirow{2}{*}{ BFA } & \multicolumn{2}{|c|}{$\begin{array}{l}\text { SHJO: friction } \\
\text { angle }\left({ }^{\circ}\right)\end{array}$} & \multicolumn{2}{|c|}{$\begin{array}{l}\text { SHJO: cohesion } \\
\text { (MPa) }\end{array}$} & \multicolumn{3}{|l|}{ UCM } \\
\hline & & Peak & Residual & Peak & Residual & $\begin{array}{l}\text { UCS } \\
\text { (MPa) }\end{array}$ & $\begin{array}{l}\text { E } \\
\text { (GPa) }\end{array}$ & $v$ \\
\hline No. of samples & 17 & 17 & & & & 33 & & \\
\hline Minimum & $30^{\circ}$ & 17 & 19 & 0.1 & 0.0 & 200 & 142 & 0.178 \\
\hline Maximum & $41^{\circ}$ & 34 & 34 & 0.3 & 0.4 & 295 & 167 & 0.26 \\
\hline Mean & $37^{\circ}$ & 23 & 26 & 0.2 & 0.1 & 250 & 150 & 0.23 \\
\hline Stdev & $3^{\circ}$ & 5 & 4 & 0.08 & 0.09 & 21 & 6 & 0.015 \\
\hline $\operatorname{CoV}(\%)$ & $8 \%$ & $21 \%$ & $15 \%$ & $40 \%$ & $90 \%$ & $8 \%$ & $12 \%$ & $6 \%$ \\
\hline
\end{tabular}




\subsection{Shear zone laboratory testing}

Soil testing on the shear zone infilling material was carried out including consolidated undrained (CU) triaxial test and in situ vane tests. The undrained shear strength was obtained as $\mathrm{Su}=18 \mathrm{kPa}$, while the effective friction angle $\phi^{\prime}=28^{\circ}$. Results of the consolidation were also provided and showed a post-consolidation volumetric strain of about $17 \%$.

\subsection{Distinct element modelling}

Numerical modelling was utilised to carry out the analysis given the complex nature of the problem and the associated failure mechanisms. The distinct element method (DEM) was preferred due primarily to its inherent capability to incorporate and handle a large number of distinct structures.

To explicitly model tensile fracturing, the model was subdivided into smaller blocks known as voronoi tessellation. This was a sine qua non since the DEM only operates on entirely closed blocks and cannot create new fractures rather than those predefined during the model construction. The voronoi blocks can interact with each other along their boundaries at specific points known as contacts.

Using DEM to investigate the behaviour of jointed pillar is not uncommon (Esterhuizen 1997, 2000; Elmo 2006). However, the stochastic representation of the joints into the models, also known as discrete fracture network (DFN), and the explicit modelling of the fracturing process are relatively new. Elmo (2006) attempted using the hybrid finite element/distinct element (ELFEN) code. Zhang (2014) used the particle flow code (PFC) in 3D to analyse the effects of jointing on hard rock pillars, while Preston (2014) undertook similar modelling in 2D using the Universal Distinct Element Code (UDEC) with a trigon tessellation background to simulate subsequent fracturing.

\subsection{Discrete fracture network}

Fractures are often deterministically represented that is where faults are explicitly modelled by specifying their real location, orientation and direction. It is possible to consider hundreds of individual fractures in this manner, but problems may arise when the number of joints become in the order of thousands. In addition, even the most extensive mapping exercise will not account for every joints. Or, in some instances the areas being designed have not been mined yet and therefore there are not exposed faces available for mapping specifically joints in that area. Often, the mapping area will only be a sample of the entire population of structures at large that can be used to statistically infer the joint characteristics across the entire study area.

A discrete fracture network (DFN) model is a statistical description of joints. A single DFN model may have multiple realisations obeying all the statistical description of the DFN model, i.e. input probability distribution functions.

Figure 5 illustrates the DFN generation process followed in this study. The DFNs were created in the program 3DEC version 5.0 (ITASCA Consulting 2013). For a better control of the process, the joints were generated on a joint set basis rather than all at once. The fracture orientation, size and position distributions of each joint set were provided in form of a template as required by 3DEC. Combining all the joint sets yielded the desired DFN realisation. The process of generation of a joint set was eventually halted when a fracture density indicator was exceeded. In this study, $\mathrm{P}_{32}$, the total area of surface in the volume unit, was used which is a measure of the total area of fractures contained in a unit volume and was computed from the linear fracture intensities, $\mathrm{P}_{10}$ measured onsite. 


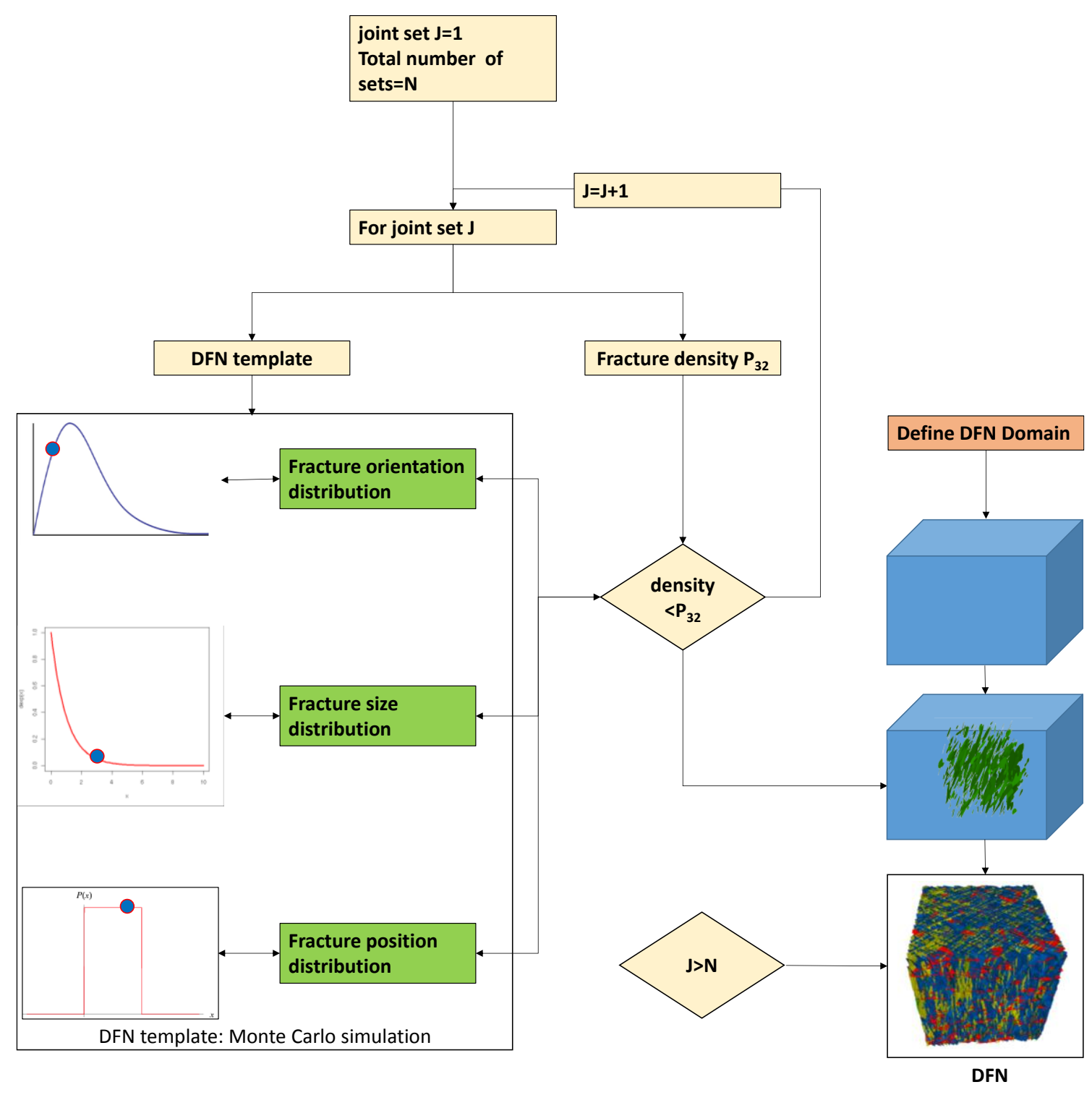

Figure 5 Schematic of the construction of a 3D DFN in 3DEC

The pillar region within the 3D DFN was rotated and aligned with the orebody dip direction and perpendicular slices were taken. The traces along the $2 \mathrm{D}$ sections were exported in a data file and subsequently imported into UDEC using a program written in UDEC embedded programming language, FISH.

The fracture orientation used in the DFN and their respective variability were as presented in Table 1. Amongst the orientation distributions currently available in 3DEC, the Fisher distribution was deemed appropriate to fit the fracture orientation data. The Fisher distribution requires the means dip and dip direction and the coefficient of dispersion $\mathrm{K}$.

The fracture length were considered to follow a power law distributions with maximum and minimum length of 14 and $5 \mathrm{~m}$, respectively. This information was estimated based on the mapping data and underground observations. The fracture position within the DFN domain was defined as a uniform distribution, whereby every position within the DFN domain is given equal chance to be selected as centre of the fracture.

As part of the DFN validation process, the distribution of spacing from the logging data was compared to that from the DFN. As explained by Priest and Hudson (1981), the spacing from the the logging was found to follow a negative exponentional distribution and that the spacing along imaginary boreholes within the DFN domain followed a similar distribution. Figure 6 shows the spacing distributions obtained from logging data and in 
the DFN. It is important to note that the purpose of the validation was not to calibrate the spacing values but rather to verify that the statistical distributions shapes were similar in both cases.
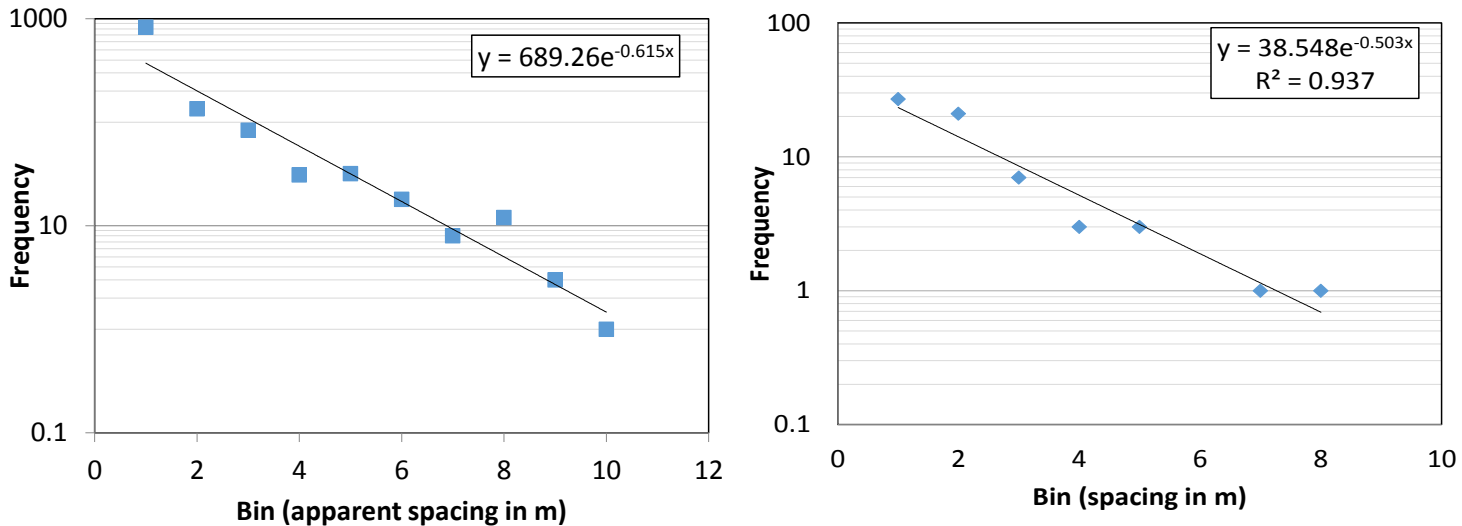

Figure 6 DFN validation: spacing distribution from logging data (left) and from DFN (right)

Table 3 summarises the $P_{32}$ calculation for each joint set based on the fracture frequency $P_{10}$ measured along the vertical boreholes logged, and scanlines mapped on strike and dip. The relationship between $P_{32}$ and $P_{10}$, $C_{10}$, was obtained by simulating the borehole and scanline within the DFN domain and measure $P_{10}$ at various values of $P_{32}$. The inverse of that relationship was used to estimate $P_{32}$ from the real data. An average $P_{32}$ value was ultimately used to account for the different $P_{32}$ values according to the scanline orientation.

Table 3 Results of the estimated volumetric intensity $\mathrm{P}_{32}$ corresponding to each joint set mapped and logged at P4

\begin{tabular}{|c|c|c|c|c|c|c|}
\hline Joint Set & $\begin{array}{l}\text { Scanline } \\
\text { orientation }\end{array}$ & $P_{10}$ & $\begin{array}{l}\text { Estimated } \\
C_{10}\end{array}$ & $P_{32}$ & $\begin{array}{l}\text { Averaged } \\
\mathbf{P}_{32}\end{array}$ & $\begin{array}{l}\text { Modelled } \\
P_{32}\end{array}$ \\
\hline \multirow[t]{3}{*}{ Set 1} & Dip & 2.75 & 1.15 & 2.81 & 2.22 & 2.2 \\
\hline & $\begin{array}{l}\text { Vertical } \\
\text { borehole }\end{array}$ & 0.16 & 10.5 & 1.64 & & \\
\hline & Strike & & 1.56 & & & \\
\hline \multirow[t]{3}{*}{ Set 2} & Dip & & 0.97 & & & \\
\hline & $\begin{array}{l}\text { Vertical } \\
\text { borehole }\end{array}$ & 0.46 & 3.09 & 1.42 & & \\
\hline & Strike & 0.17 & 5.92 & 1.75 & 1.21 & 1.2 \\
\hline \multirow[t]{3}{*}{ Set 3} & Dip & & 2.3 & & & \\
\hline & $\begin{array}{l}\text { Vertical } \\
\text { borehole }\end{array}$ & 0.16 & 4.4 & 0.7 & & \\
\hline & Strike & 1.75 & 1.06 & 1.85 & 1.23 & 1.2 \\
\hline \multirow[t]{3}{*}{ Set 4} & Dip & & 7.33 & & & \\
\hline & $\begin{array}{l}\text { Vertical } \\
\text { borehole }\end{array}$ & 1.01 & 0.95 & 0.96 & & \\
\hline & Strike & & 6.83 & & 0.96 & 1 \\
\hline
\end{tabular}




\subsection{Numerical model set-up}

A series of sections coincident with the dip orientation were made through the DFN. The resulting 2D section lines were imported into the software UDEC for stability analysis using a user defined function in the built-in programming language FISH. Figure 7 shows the model set-up in UDEC together with the boundary conditions. A constant displacement velocity $(v=0.05 \mathrm{~m} / \mathrm{s})$ was applied to the top of the model.

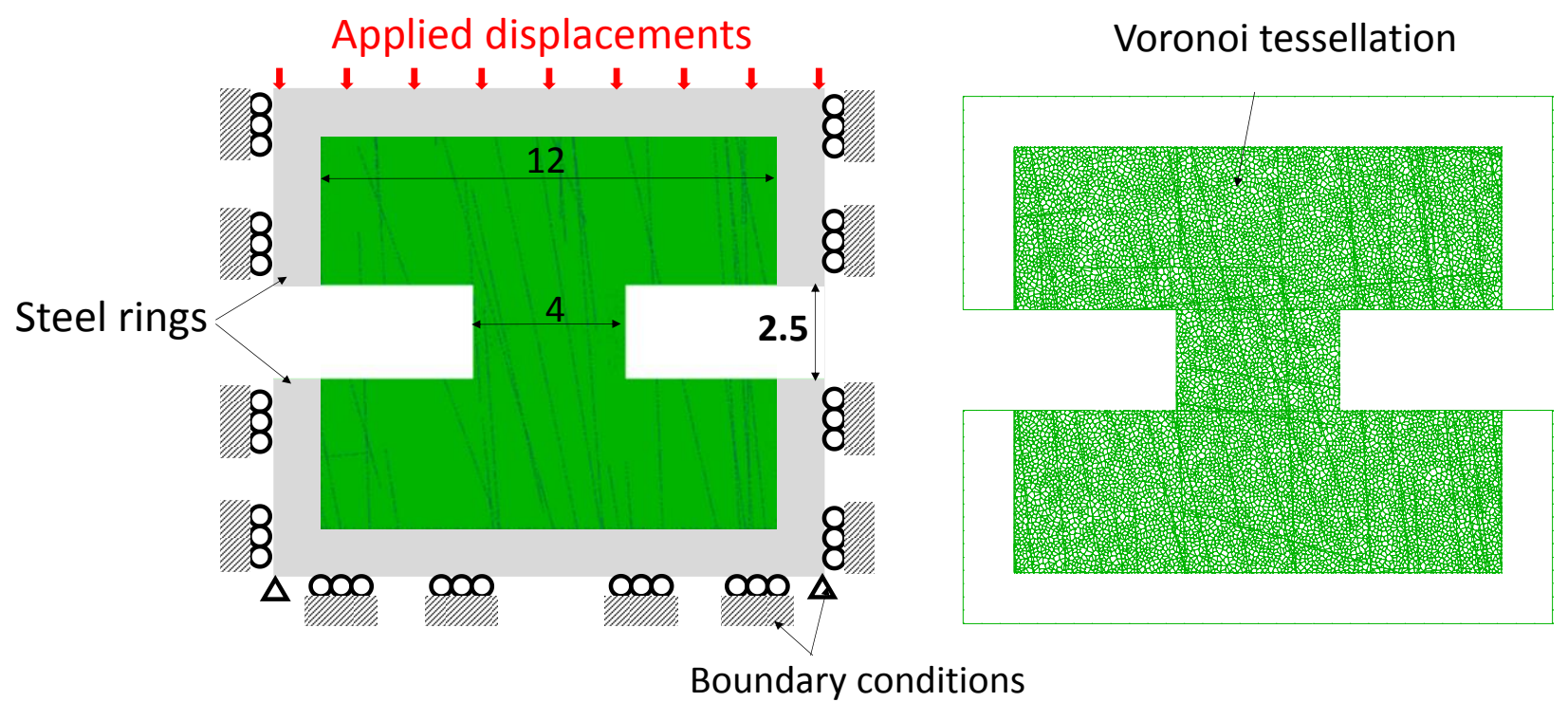

Figure 7 Pillar model set-up

Even though the intent was to analyse as many DFN realisations as possible, this proved difficult since the runtime of the models remained very high in spite of numerous optimisation attempts. Therefore, for this analysis only two DFN (DFN 1 and DFN 2) were used and selected so as to represent specific geotechnical conditions. For instance, DFN 1 represents areas with low-angle joint, whereas DFN 2 was intended to represent areas with only the sub-vertical joint sets. In addition, four shear configurations were considered, resulting in the eight geotechnical conditions represented in Figure 8. 


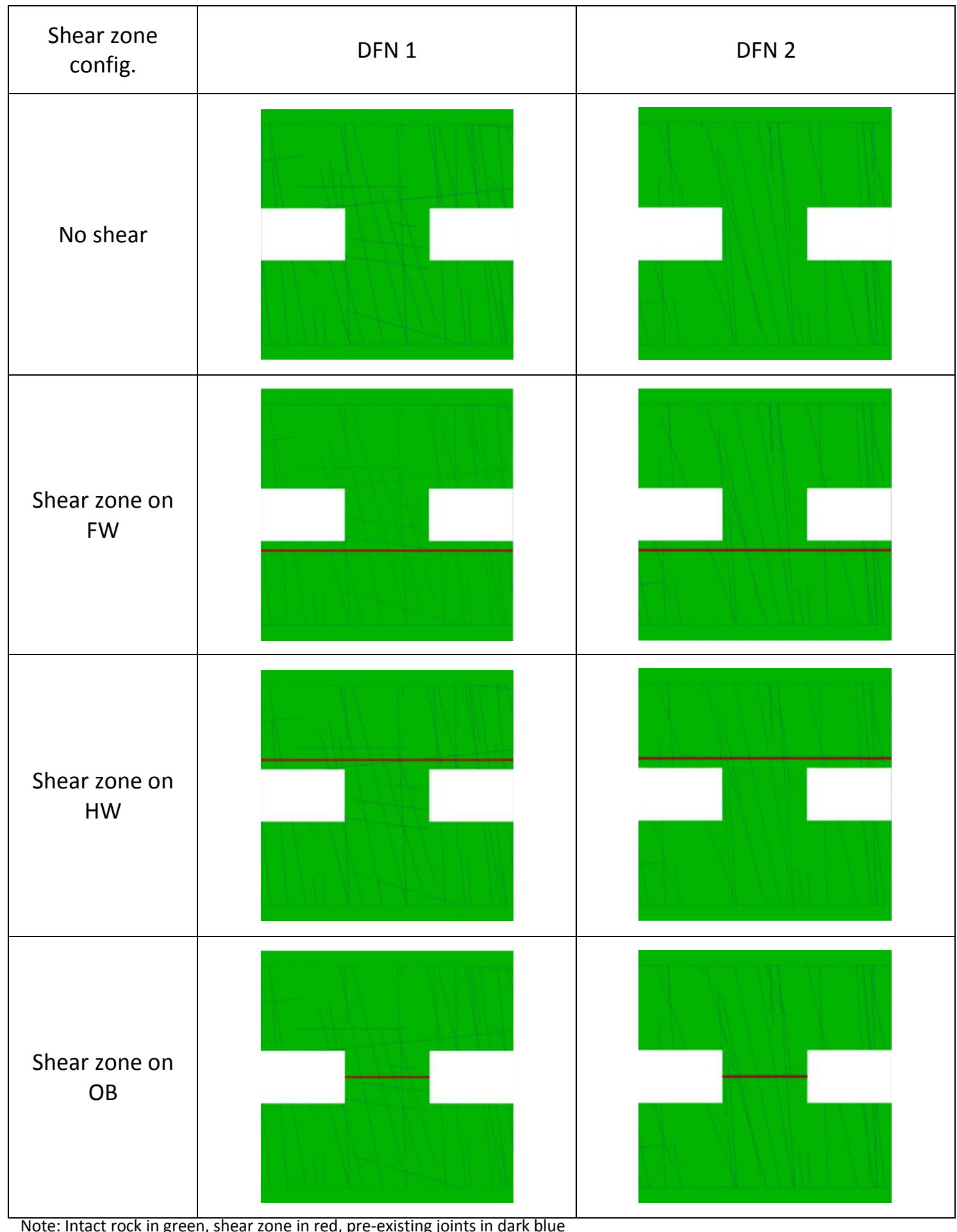

FW: Footwall, HW: Hanging wall; OB: orebody

\section{Figure 8 Geotechnical conditions considered in the analysis}

\subsection{Intact rock calibration}

The intact rock and the fracturing therein were simulated using a voronoi tessellation network. The properties of the contacts between the voronoi cells were defined such that the model reproduced some rock properties measured in the laboratory. A series of uniaxial compressive and tensile Brazilian strength tests were simulated in UDEC and the properties of the voronoi blocks and contacts were adjusted until a reasonable correlation was obtained between measured and modelled strengths. It is important to note that 
voronoi blocks were kept elastic and failure was allowed to take place only at the contacts. The voronoi tessellation properties used in the analysis are summarised in Tables 4 and 5 . The properties of the steel platens are also presented in Table 6.

Table 4 Voronoi block properties

\begin{tabular}{ll}
\hline Parameter & Value \\
\hline Density $\left(\mathrm{kg} / \mathrm{m}^{3}\right)$ & 3,300 \\
\hline Elastic modulus (GPa) & 150 \\
\hline Poisson's ratio & 0.23 \\
\hline
\end{tabular}

Table 5 Voronoi contact properties

\begin{tabular}{ll}
\hline Voronoi contact parameters & Value \\
\hline Cohesion $(\mathrm{MPa})$ & 50 \\
\hline Residual cohesion $(\mathrm{MPa})$ & 0 \\
\hline Friction $\left(^{\circ}\right)$ & 0 \\
\hline Residual friction angle $\left(^{\circ}\right)$ & 25 \\
\hline Tensile strength $(\mathrm{MPa})$ & 5 \\
\hline Residual tensile strength $(\mathrm{MPa})$ & 0 \\
\hline Normal stiffness $(\mathrm{GPa} / \mathrm{m})$ & 1,500 \\
\hline Shear stiffness $(\mathrm{GPa} / \mathrm{m})$ & 600 \\
\hline
\end{tabular}

Table 6 Steel platen properties

\begin{tabular}{ll}
\hline Parameter & Value \\
\hline Density $\left(\mathrm{kg} / \mathrm{m}^{3}\right)$ & 7,600 \\
\hline Elastic modulus (GPa) & 200 \\
\hline Poisson's ratio & 0.25 \\
\hline
\end{tabular}

\section{$2.9 \quad$ Joint material properties}

The joint material properties were derived from the results of the shear box tests carried out on joint specimens. Since the version of UDEC used in the analysis was not Barton-Bandis joint constitutive model enabled, Mohr-Coulomb was used instead. The friction angle and cohesion from the shear box tests was conservatively used as a first estimate for the joint strength properties. However, it was later observed that under these joint properties, the expected failure mechanisms such as footwall heave did not occur although well-developed in other pillar models without joints. Amongst others, a sensitivity analysis was carried out on the joint strength properties on suspicion of their values being too low. The results confirmed that the overly conservative joint strength used in the previous analyses indeed precluded the development of the expected failure mechanisms. A fit through the Barton-Bandis model was used to derive more realistic Mohr-Coulomb strength properties to assign to the joints in the models taking into consideration the large scale characteristics of the joints. The Barton-Bandis model requires parameters such as, the joint wall compressive strength (JCS) and joint roughness coefficient (JRC). The maximum confinement was taken equal to a typical peak average pillar strength of $160 \mathrm{MPa}$ and the scaling length was assumed equal to the average 
joint length of $14 \mathrm{~m}$. This resulted in equivalent Mohr-Coulomb properties for the joint of $2.5 \mathrm{MPa}$ and $26^{\circ}$ for the apparent joint cohesion and the friction angle, respectively.

The normal and shear stiffness of the joints proved more complicated to assign because UDEC tends to use the stiffness to compute internal parameters such as the time step. Large contrasts in stiffness often results in much longer time step, hence longer simulations. Therefore, although the normal stiffness of pre-existing joints is known to be in the order of $1 \mathrm{GPa}$ and the shear stiffness roughly one fiftieth of the normal stiffness, applying these values in the model proved simply impractical as it led to lengthy runtime. Sensitivity analysis was conducted over a range of much higher joint stiffness values and the effect on the pillar failure mechanisms was used as the deciding factor. The joint mechanical properties ultimately used in the model are summarised in Table 7.

Table 7 Joint mean strength properties

\begin{tabular}{ll}
\hline Pre-existing joint material properties & Value \\
\hline Cohesion $(\mathrm{MPa})$ & 2.5 \\
Friction angle $\left(^{\circ}\right)$ & 26 \\
Normal stiffness $(\mathrm{GPa} / \mathrm{m})$ & 1,000 \\
\hline Shear stiffness $(\mathrm{GPa} / \mathrm{m})$ & 100 \\
\hline
\end{tabular}

\subsection{Shear zone properties}

The cam-clay constitutive model was considered to be the ideal constitutive model to simulate the behaviour of the shear structure clay-rich infilling material. However, numerical instability arose unexpectedly when such material was included in the pillar models, raising concerns about the suitability going forward of this constitutive model. A Mohr-Coulomb model seemed to pose similar problem. The interim solution was to use an elastic model instead with bulk and shear modulus values equivalent to those one would have obtained by using directly the cam-clay model. In reality, the clay is expected to behave elastically only below limited ranges of mean effective and differential stress. As suggested by simulation results of models with the cam-clay explicitly modelled, the state of the clay will in all likelihood plot above the yield line for most of the simulations with corresponding dilation or compaction depending on the mean effective stress level. However, the model seemed not to be able to handle the resultant plastic flow and instability arose. By assuming an elastic behaviour, the actual deformations within the clay layer were arguably underestimated, but nonetheless, numerical stability was restored.

As water dripping and seepage was reported in the areas where failure initiated, and taking into account the low clay hydraulic conductivity, undrained conditions were considered for the analysis. Deriving elastic properties for the shear zone involved under undrained conditions involved, the computation of the matrix bulk modulus and the undrained bulk modulus assuming the Biot coefficient at alpha $=1$. The shear modulus was taken as one tenth of the undrained modulus and the wet density was used instead of the dry one. This calculation was automatically performed using FISH. The inputs for the bulk and shear modulus calculation are the cam-clay properties presented in Table 8. The cam-clay consolidation pressure and specific volume together with the slopes of the consolidation and swelling lines were obtained from a fit through the laboratory results as indicated in Figure 9.

Where the physics of the problem allowed, such as where shear occurs in the footwall, the shear zone was modelled as a continuum. Where detachment through the shear zone was essential, then largely spaced artificial discontinuities were placed into the shear zone. The contacts along these artificially placed discontinuity were given strength properties representative of consolidated undrained conditions (friction $=0$ and undrained cohesion $c_{u}=18 \mathrm{kPa}$ ). The same normal and shear stiffness of the voronoi tessellation contacts were used. 
Table 8 Shear mechanical properties

\begin{tabular}{lll}
\hline Shear zone material properties & Value \\
\hline$p_{0}(\mathrm{kPa})$ & 32 \\
\hline $\mathrm{p}_{\mathrm{co}}(\mathrm{kPa})$ & 300 \\
\hline $\mathrm{p}_{1}(\mathrm{kPa})$ & 1 \\
\hline $\mathrm{V}_{\lambda}$ & 5.2 \\
\hline$\lambda$ & & 0.29 \\
\hline $\mathrm{K}$ & & 0.035 \\
\hline Cohesion $(\mathrm{kPa})$ & & 18 \\
\hline Friction angle $\left(^{\circ}\right)$ & & 0 \\
\hline & & 18 \\
\hline
\end{tabular}

Figure 9 Isotropic consolidation test results and inference of cam-clay model parameter

\section{Results and discussion}

The results and discussion of the analysis have been subdivided into three sections. The first section presents the pillar failure mechanisms obtained in UDEC. The second section shows the effect does enlarging or reducing pillar have within a given geotechnical condition, i.e. DFN and shear structure configuration. The third section shows the effect does shifting between geotechnical domains have considering the same pillar size.

\subsection{Pillar failure mechanisms}

Figure 10 illustrates failure mechanisms obtained in UDEC and how closely the 2D modelling replicated the pillar behaviour associated with the shear zone such as footwall heave, hanging wall fallouts, bulging of pillar walls and tensile fracturing, to mention the most important. The figures also show the role that the joint configuration (DFN) plays in the manifestation of a particular failure mechanism. For instance, it can be seen that foot heave tends to develop easily in DFN 2 where all joint sets are nearly vertical without the low angle joints. 


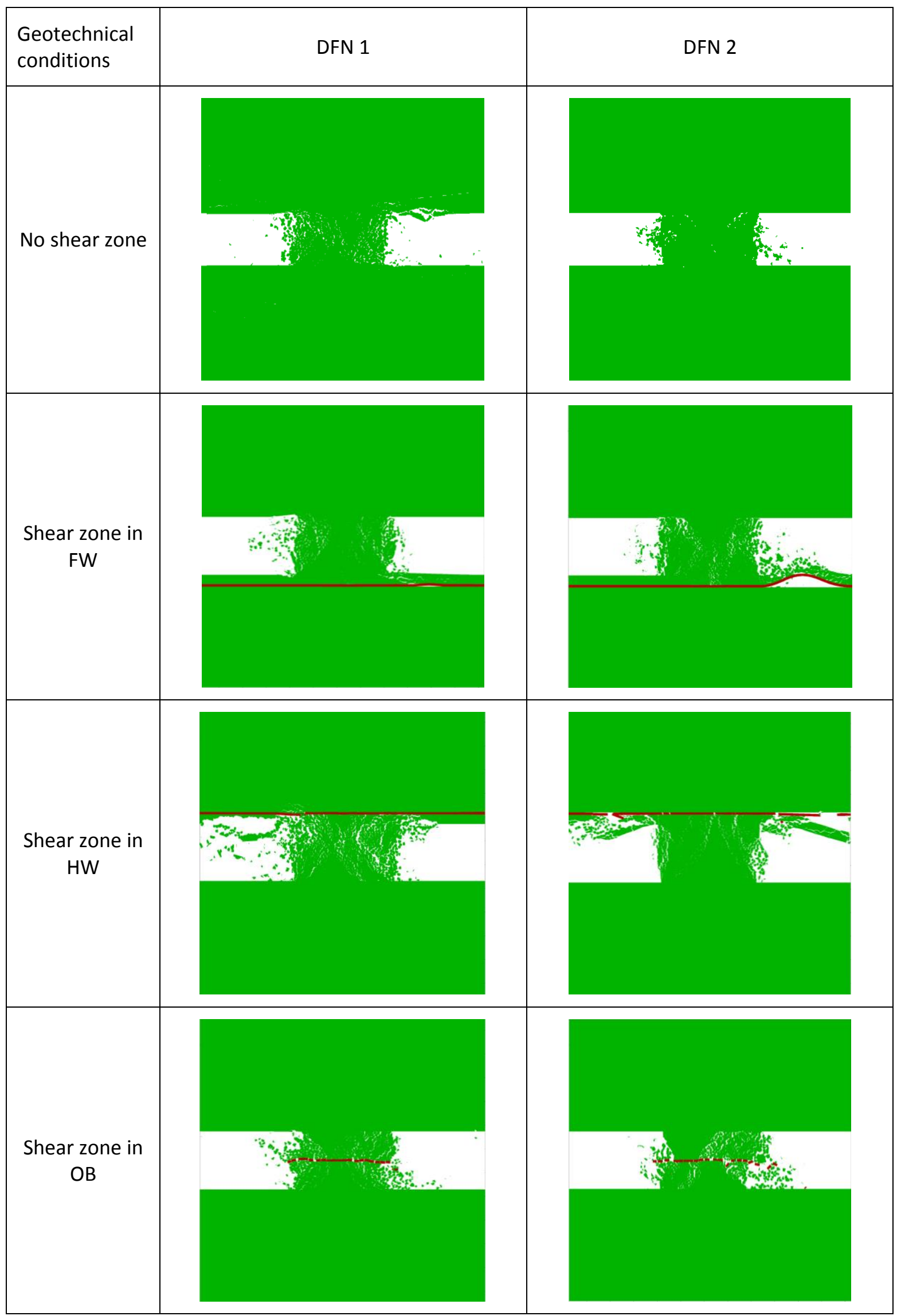

Figure 10 Key failure mechanisms 


\subsection{Effect of pillar size}

Figure 11 shows stress/displacement curves for jointed pillar models with and without shear zone in DFN 1 and DFN 2. For ease of comparison, both results of DFN 1 and DFN 2 are represented together. This representation helps draw a contrast between different pillar sizes but also different DFNs. The results are reported both in terms of the actual modelled pillar size and effective pillar width, which in this case is equal to twice the modelled pillar width (Wagner 1980). Expectedly, in DFN 1, in the absence of shear zone, increasing the pillar size results in an increase in peak pillar strength (Esterhuizen 1997). In addition, for DFN 1, the model with sub-horizontal joint set, the stiffness of the pillar varies significantly with the pillar size, however, no clear trend was identified. The stiffness of the $4 \mathrm{~m}$ modelled pillar appeared lower than for the $20 \mathrm{~m}$, while the $6 \mathrm{~m}$ wide pillar seems stiffer than both the 2 and $4 \mathrm{~m}$ pillars. The reason for this remains unknown.
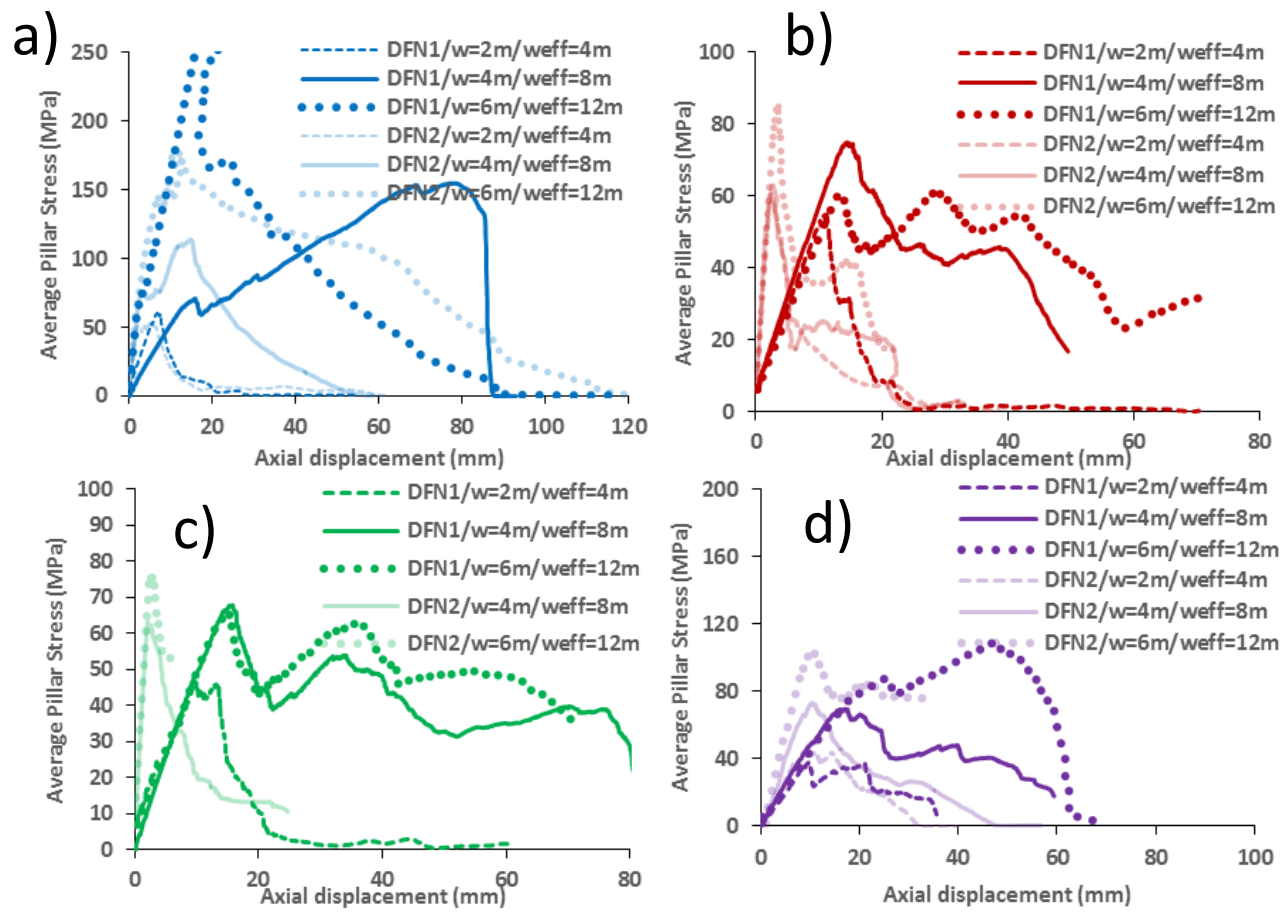

Figure 11 Results of model pillars: (a) without shear zone; (b) with shear zone located in the footwall; (c) in the hanging wall; and, (d) in the orebody

In DFN 2, which has sub-vertical joint sets only, the response to increasing pillar size seemed more intuitive. The stiffness of the pillars was found to be the same for all pillar sizes, and is in general much higher than for pillars with DFN1. In addition, the post-peak behaviour of the pillars in absence of the shear zone were also found to be intuitive with failure becoming relatively less brittle or more ductile as the pillar size increases. In spite of the shear structure in the footwall or hanging wall, pillars of all sizes appeared very stiff. The peak pillar strength is attained after relatively small pillar closure. However, most curves also exhibited either a second peak or a residual strength in shape of a plateau. In analysing these results, cognizance was taken of the fact that in reality some hanging closure is inevitable and that very stiff pillar will most probably operate in the post peak region of the curve. In these cases, the second peak (or the residual strength) was then considered to be more representative of the actual pillar strength.

\subsection{Effect of change of geotechnical conditions}

Figure 12 show in turn the behaviours of a 2, 4 and $6 \mathrm{~m}$ wide pillar in the geotechnical conditions identified in this study. The peak strength of a $2 \mathrm{~m}$ is the lowest where the shear zone is in the orebody with low angle joints transecting the pillar. However, the pillar appeared softer under these conditions with a broader stress/displacement curve and multiple peaks and a residual strength plateau extending up to almost $40 \mathrm{~mm}$ of pillar vertical closure. Therefore, in spite of the low peak strength, the option where the shear zone is in 
the orebody can be viewed as the most favourable. The $2 \mathrm{~m}$ wide pillars are also in general softer in the presence of low angle joints except for where the shear zone is in the $\mathrm{OB}$, in which case the pillar appears softer even without the low angle joints. The effect of the shear zone on the stiffness of the $2 \mathrm{~m}$ wide pillar is only noticeable in the presence of low angle joints. Without the low angle joints, all $2 \mathrm{~m}$ pillar models appear particularly stiff apart from where shear zone is in the OB. Apart from the scenarios where shear zone is in the $\mathrm{OB}$, all $2 \mathrm{~m}$ pillar models tend not to sustain a residual strength over a significant range of vertical displacements (closure).
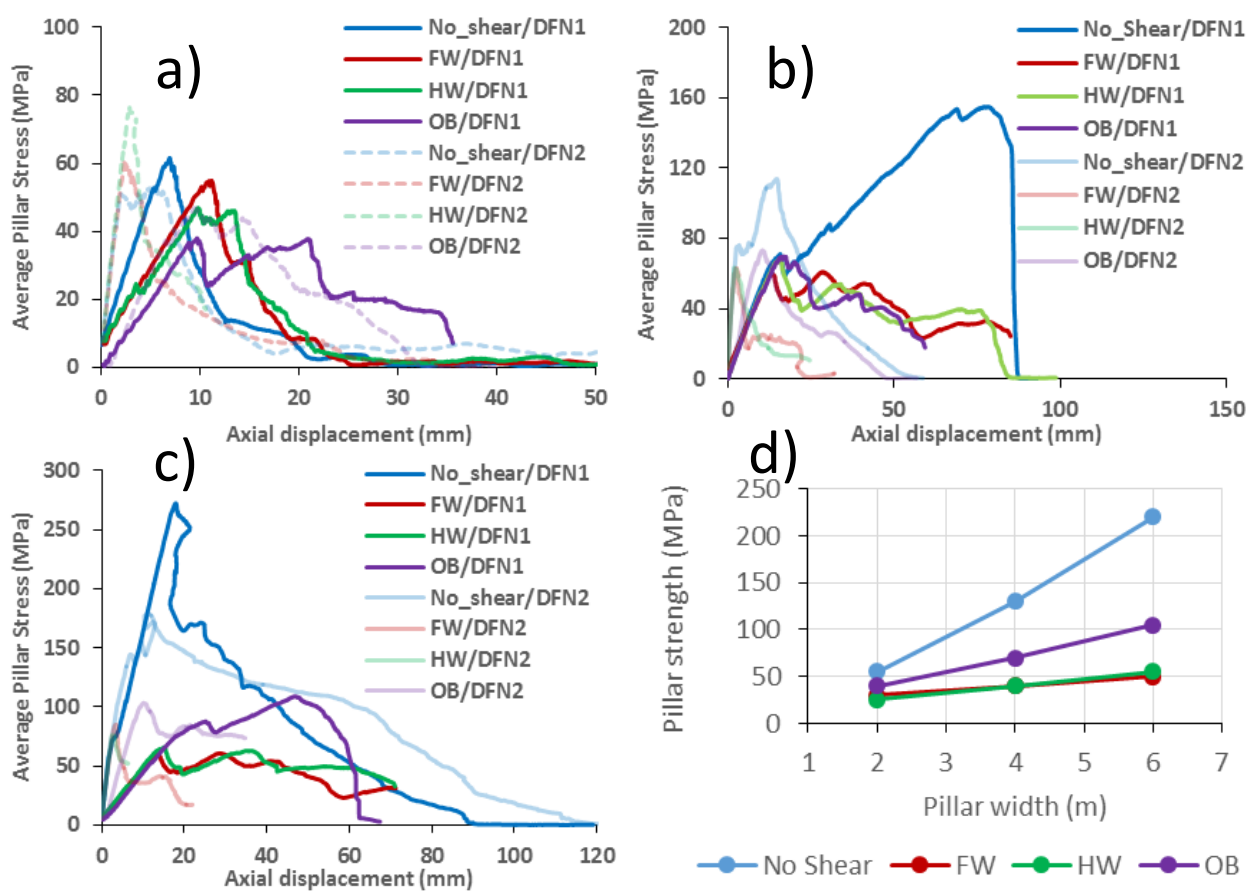

Figure 12 Results of model pillars of different widths in various geotechnical conditions: (a) $2 \mathrm{~m}$ wide pillars; (b) $4 \mathrm{~m}$ wide pillars; and, (c) $6 \mathrm{~m}$ wide pillars. (d) average values of pillar strength for DFN 1 and DFN 2 in the different geotechnical conditions as a function of the pillar width

For the $4 \mathrm{~m}$ pillars, it can be seen that options with shear zone in FW, HW and OB are not significantly different from each other from a pillar strength point of view even though the failure mechanisms differ. However, the model without shear zone exhibited strain-hardening up to closure of about $80 \mathrm{~mm}$ prior to fail in a brittle manner.

Owing to the presence of the low angle joints in DFN 1, the $6 \mathrm{~m}$ pillar models tended to be softer except for the model without shear where the pillar is seen to be significantly stiffer. It is also seen that the stiffness of this particular pillar remains the same in DFN 2, which emphasize the notion that the effect of jointing reduces as the pillar size increases. The $6 \mathrm{~m}$ modelled pillar without shear zone has a peak strength of about $270 \mathrm{MPa}$ reached at a pillar closure of $20 \mathrm{~mm}$. Beyond the peak strength, the pillar fails almost in the brittle manner. Failure in this case involves punching of the pillar into the foot and hanging walls, which is indicated on the graph by negative axial pillar displacement variations.

In addition, $6 \mathrm{~m}$ pillars with shear in the $\mathrm{OB}$ appeared stronger than cases with shear on the FW and HW, the peak strength being of about $110 \mathrm{MPa}$. A first peak of $85 \mathrm{MPa}$ is attained after $25 \mathrm{~mm}$ of closure then the pillar strain-hardens to the second peak strength of $110 \mathrm{MPa}$ at pillar closure of $40 \mathrm{~mm}$. Beyond the second pillar peak strength, the pillar fails suddenly. The peak strength of modelled pillars with shear zone on the FW and HW seem not to exceed $65 \mathrm{MPa}$, however, in these cases, the pillar strength remains almost constant up to the end of the experiment, even after footwall heave, hanging wall fallouts and tensile fracturing have occurred.

Figure 12 also summarises the average values of pillar strength of both DFN 1 and 2 in the different geotechnical conditions examined in this study. It is evident from the figure that the shear structure precludes 
the gain in strength of the pillar as a result of increasing the width and that pillars will need to be substantially larger to achieve a similar strength as in situations without shear structure but it can also be seen that the adverse effect of the shear structure tends to be more pronounced where the shear is in the FW and HW than in the orebody. The same results are tabulated in Tables 9 and 10. The pillar strength ratios in the tables indicate either the gain or reduction obtained as a result of a change in geotechnical conditions or pillar size, using a particular case as reference. As in practice, it is easier to design pillar using empirical methods, the pillar strength ratios in the tables were proposed as a means to adjust the design values from the empirical approach to account for the effect of the shear structure.

Table 1 Summary of average pillar strength (shear position versus pillar width)

\begin{tabular}{llll}
\hline & \multicolumn{3}{l}{ Pillar (minimum width/effective width) } \\
Model & $\mathbf{2 / 4} \mathbf{~}$ & $\mathbf{4 / 8} \mathbf{~ m}$ & $\mathbf{6 / 1 2} \mathbf{~}$ \\
\hline & Pillar strength (MPa) & & \\
\hline No shear & 55 & 130 & 220 \\
\hline FW & 30 & 40 & 50 \\
\hline HW & 25 & 40 & 55 \\
\hline OB & 40 & 70 & 105 \\
\hline No shear & Pillar strength ratio & & \\
\hline FW & $100 \%$ & $100 \%$ & $100 \%$ \\
\hline HW & $54 \%$ & $30 \%$ & $22 \%$ \\
\hline OB & $45 \%$ & $30 \%$ & $25 \%$ \\
\hline
\end{tabular}

Table 2 Summary of average pillar strength (pillar width versus shear position)

\begin{tabular}{lllll}
\hline $\begin{array}{l}\text { Pillar } \\
\left(\mathbf{w}_{\text {min }} / \mathbf{w}_{\text {eff }}\right)^{*}\end{array}$ & $\begin{array}{l}\text { Model } \\
\text { No shear } \\
\text { Pillar strength }(\mathbf{M P a})\end{array}$ & FW & HW & OB \\
\hline $2 / 4 \mathrm{~m}$ & 55 & 30 & 25 & 40 \\
\hline $4 / 8 \mathrm{~m}$ & 130 & 40 & 40 & 70 \\
\hline $6 / 12 \mathrm{~m}$ & 220 & 50 & 55 & 105 \\
\hline & Pillar strength ratio & & \\
\hline $2 / 4 \mathrm{~m}$ & $42 \%$ & $75 \%$ & $63 \%$ & $57 \%$ \\
\hline $4 / 8 \mathrm{~m}$ & $100 \%$ & $100 \%$ & $100 \%$ & $100 \%$ \\
$6 / 12 \mathrm{~m}$ & $170 \%$ & $125 \%$ & $138 \%$ & $150 \%$ \\
\hline
\end{tabular}

$* \mathrm{w}_{\min }=$ minimum width; $\mathrm{w}_{\mathrm{eff}}=$ effective width 


\section{Conclusion}

The type of modelling presented in this paper is still in its infancy and the results thereof may require further refinement. The preliminary results however have accurately captured phenomena associated with pillar failure in the area under investigation, including footwall heave, hanging wall fallouts, bulging of pillar walls and tensile fracturing, to mention a few. The model even captured to some extent the way rock blocks detach from the pillar and hanging walls as the displacements increase.

However, it is important to mention that beyond the pillar peak strength, the model enters a strain softening region where the response is seemingly dependent on virtually all the numerical modelling inputs such as the loading velocity, the voronoi tessellation size and the damping type and magnitude. The method is therefore less robust and a great deal of calibration and model validation based on practical experience is required.

The issue of time steps in UDEC required significant attention to allow for realistic behaviour to develop that is detachment and sliding of blocks and adequate load re-distribution between time steps. This was partially addressed through the use of a relatively slow loading rate and the adjustment of joint normal and shear stiffness.

The run time remained low in spite of a two stage loading implemented for optimisation purposes. This limitation did not allow the analysis of the number of model required to obtain a pillar strength statistically representative. This problem could have been partially alleviated had UDEC version 6 been used instead of version 5 as in this study. UDEC version 6 has 64 bit processor architecture, which could have improved computational run times.

Even though there is a large uncertainty that remains in the UDEC models, the fact that most pillar failure mechanisms could be satisfactorily modelled is in itself promising and implies that not only the approach can be useful going forward for generating understanding about the underlying mechanics but can also be used for comparative analysis such as for instance the evaluation of different support options.

\section{Acknowledgement}

We thank Zimplats, Ngezi mine for the opportunity to carry out this project and for providing all the necessary information data. We are immensely grateful to Mr Les Gardner from Implats for his guidance during the course of the project, for providing the historical intact rock testing database and for helping with the collection of samples and the supervision of the laboratory testing campaign.

\section{References}

Elmo, D 2006, Evaluation of a hybrid FEM/DEM approach for determination of rock mass strength using a combination of discontinuity mapping and fracture mechanics modelling, with particular emphasis on modelling of jointed pillars, PhD thesis, University of Exeter, Exeter.

Esterhuizen, G 1997, 'Investigation into the effect of discontinuities on the strength of coal pillars', The Journal of The South African Institute of Mining and Metallurgy, vol. 97, March/April 1997, pp. 57-62.

Esterhuizen, G 2000, 'Jointing effects on pillar strength', in SS Peng \& C Mark (eds), Proceedings of the 19th Conference on Ground Control in Mining, 8-10 August 2010, Morgantown, West Virginia University, Morgantown, pp. 286-290.

ITASCA Consulting Group 2013, 3DEC User's manual - Discrete Fracture Networks in 3DEC, ITASCA Consulting Group, Minneapolis.

Preston, RP 2014, Application of Photogrammetry to Estimates of Mine Pillar Damage and Strength, PhD thesis, Simon Fraser University, Vancouver.

Priest, SD \& Hudson, JA 1981, 'Estimation of discontinuity spacing and trace length using scanline surveys', International Journal of Rock Mechanics and Mining Science and Geomechanics Abstracts, vol. 18, pp. 183-197.

Rocscience Inc. 2012, Dips, version 6.0, Rocscience Inc., Toronto.

Wagner, H 1980, 'Pillar design in coal mines', The Journal of the South African Institute of Mining and Metallurgy, vol. 80, pp. 37-45.

Zhang, Y 2014, Modelling Hard Rock Pillars Using a Synthetic Rock Mass Approach, PhD thesis, Simon Fraser University, Vancouver. 